\title{
Affective Priming in Political Campaigns: How Campaign-Induced Emotions Prime Political Opinions
}

\section{Rinaldo Kühne, Christian Schemer, Jörg Matthes and Werner Wirth}

University of Zürich

\begin{abstract}
Campaign priming is generally assumed to function through the activation of memory content. By focusing on specific issues or issue aspects, campaigns render corresponding cognitive concepts more accessible and hence influence which concepts are likely to be used in subsequent evaluation processes. Thus, priming is mainly understood as a cognitive process. In the present study we investigate the impact of campaigninduced emotions on opinion formation. We argue that emotions may activate cognitive content which may in turn influence political judgments. Our analyses support the hypothesis that political campaigns may influence public opinion not only through cognitive priming but also through affective priming.
\end{abstract}

In their seminal work on priming, Iyengar and Kinder (I987) argued that "by priming certain aspects of national life while ignoring others, television news sets the terms by which political judgments are rendered and political choices made" (p. 4). Based on Iyengar and Kinder's conceptual groundwork, many studies have explored the effects of political campaigns on opinion formation and voting (e.g., Bartels, 2006; de Vreese, 2004; Druckman, 2004). In this line of research, priming is generally assumed to function through the activation of memory content. By focusing on specific issues or issue aspects, political campaigns render corresponding cognitive concepts more accessible and hence influence which concepts are likely to be used in subsequent evaluation processes (e.g., Iyengar, I990; Ju, 2005; Krosnick \& Kinder, 1990). Thus, priming is mainly understood as a cognitive process.

All correspondence concerning this article should be addressed to Rinaldo Kühne, IPMZ - Institute of Mass Communication and Media Research, University of Zürich, Andreasstrasse 15, CH-8050 Zürich, Switzerland. E-mail: r.kuehne@ipmz.uzh.ch 
Rarely are political campaigns solely about issues and arguments though. As documented by content analytic studies (e.g., De Castella, McGarty, \& Musgrove, 2009; Jerit, 2004), emotions are in fact a pervasive element of political communication used by political candidates and parties to win the attention and approval of the public. The attitudinal ramifications of emotional appeals in political campaigns are yet barely incorporated in the classical conceptualizations of campaign effects (i.e., the priming and framing perspective).

We thus propose an extension of the priming approach formulated by Iyengar and Kinder (1987), such that campaigns can also indirectly enhance the attitudinal importance of cognitions by eliciting emotions which, in turn, raise the importance of certain cognitions in the attitude formation process. In doing so, we bear on the work of Bower (I98I) who has pointed out that memory content may not only be activated by the exposure to semantic information but also by individuals' affective states. For example, good moods and positive emotions can increase the accessibility of positively valenced memory content. It is therefore suggestive to complement the cognitive priming approach with affective priming effects (Bower, I98I; Forgas, 1995): Political campaigns may influence the accessibility of cognitions not only by emphasizing certain aspects of the debated issues (e.g., Matthes, 2008). They may also influence accessibility of arguments by evoking issue-related affect and, by doing so, they have an impact on subsequent evaluations of the issue. Affective priming effects are well established in social psychology and have been demonstrated repeatedly in experimental studies (cf. Forgas, I995). However, their long-term effects during political campaigns have yet to be accounted for.

Below, we first provide a concise literature review on the role of emotions in political thinking and behavior. We discuss the different paths of affective influence on political judgment and argue that affective priming is a particularly useful approach to explain the interactive effects of emotions and political cognitions. We then turn to the illustration of the affective priming approach as an extension of the classical cognitive priming concept. Based on the associative network model of memory (e.g., Collins \& Loftus, 1975), we will argue that affective priming can be understood as an alternative form of an activation impulse within the cognitive network that renders certain memory content more accessible. Finally, we present the results of our analyses which investigated the impact of emotions during a political campaign in Switzerland. The results support the direct and interactive effects of emotions on political judgments. The implications of these emotional effects of political campaigns are discussed.

\section{The Emotional Underpinnings of Political Decision Making}

Since the opening of the psychological black box in the mid 2oth century, campaign research has essentially focused on cognitive processes. Under the 
influence of the rapid developments in information technology and the emergence of computers, the metaphor of the "information processor" has often been used to describe individuals and their judgment processes. As LeDoux (I 999) pointed out, this metaphor supported a research program that was focused rather on cognitions than on emotions, as the latter were considered illogical and thus not applicable to models of purposeful reasoning. Affect was, for the most part, seen as a simple evaluation resulting from the cognitive assessment of an object, whereas emotional judgment processes were barely considered (Zajonc, I980). Similarly, research in the realm of political decision making had a predominantly cognitive perspective (Way \& Masters, I996) and was interested in phenomena like stereotyping, cognitive heuristics, or issue voting.

Recently, interest in emotional influences on political decision making has picked up. In the course of Zajonc's (I980) criticism of the predominant cognitive focus of psychology, it has been argued that political cognition is heavily influenced by affective processes. "Primacy of affect" proponents have even claimed the prevalence of emotions within processes of political opinion formation (cf. Lodge \& Taber, 2005). Neuroscientific findings demonstrate that affective processes can also impact decision making in the absence of conscious cognition (LeDoux, I999; McDermott, 2004). It is therefore useful to conceptualize political information processing as consisting of two distinct entities, the affective and the cognitive, which typically (but not necessarily) interact when a political evaluation is fabricated (Way \& Masters, I996).

Compared to the multitude of findings on the cognitive impact of campaigns, the empirical findings about emotional effects on political judgment are still scarce. Since the I980s, a first line of research has focused the direct effects of emotion on evaluations of politicians and political issues. Abelson and colleagues (Abelson, Kinder, Peters, \& Fiske I982) were among the first researchers who examined the relationship between affect and evaluations of political candidates. They found that positive and negative affect form constructs that are independent of cognitions (e.g., trait ratings of candidates). Furthermore, they demonstrated that positive and negative emotions predict thermometer ratings of presidential candidates. As expected, positive emotions towards a candidate had a positive impact on his or her global evaluation while negative emotions were detrimental to the evaluation.

The distinctness of affective influences on political judgment has been corroborated in multiple studies which provided evidence that affect does not only influences the evaluation of political candidates (Ottati, Steenbergen, \& Riggle, I992), but also the assessment of presidential and governmental performance (Conover \& Feldman, I986), voting intention (Granberg \& Brown, I989), 
evaluations of political issues like the death penalty (Haddock \& Zanna, I998) or abortion (Breckler \& Wiggins, I99r), as well as attitudes towards social groups (Haddock, Zanna, \& Esses, I993) and political institutions (Rahn, 2000). This first line of research has primarily been interested in demonstrating that emotions have a genuine influence on political judgments and that this effect is distinct from the influence of cognition, thus explaining additional variance of political opinions. The focus on the direct effects of emotions and cognition can hence be understood as a reaction to the predominantly cognitive research tradition that did not grant emotions a place within its theoretical framework. Although these studies have produced many insightful findings, the focus on direct emotional effects turned out to have a downside: It led to a narrowed view of the attitudinal influences of emotions and cognitions because cognitive and affective processes were-implicitly or explicitlyconsidered to operate independently. This is reflected in the theoretical models that were applied: Affective influences were explained by the affect as information concept (e.g., Granberg \& Brown, I989; Rahn, 2000) or the multicomponent model of attitudes (e.g., Haddock \& Zanna, r998; Ottati et al., I992), which both conceptualize cognition and emotion as independent predictors of political judgments. As current psychological research points out, however, cognition and emotion typically interact in processes of decision making (e.g., Damasio, I994; LeDoux, I999). Recent studies in the field of public opinion have expanded their focus to the interactive effects of emotion and cognition. Marcus and MacKuen (I993) were among the first who analyzed the interplay of affect and cognition during political campaigns. They postulated that voters alternate between a thorough analysis of electoral information and a mere reliance on party affiliation, depending on the experience of enthusiasm or fear during presidential campaigns. According to their affective intelligence approach, enthusiasm signals to the individual that no particular effort has to be expended as everything is going well. Enthusiastic individuals are hence likely to depend on previously learned routines and preferences like their party affiliation and ideologies. Fear, on the contrary, is triggered when the context is unfamiliar or the outcomes are uncertain; it instructs individuals to pay careful attention to the political events as the novelty of the situation does not allow for the use of routine procedures. Emotions thus function as a swift indicator for the cognitive effort that should be expended and provide the citizen with "affective intelligence". Analyses based on the affective intelligence approach showed that enthusiasm did increase support of the own candidate. Fear was, on the other hand, not directly related to voting preference, but moderated the effect of partisanship on voting preference (Marcus \& MacKuen, I993). More precisely, intense fear reduced the reliance on the party heuristic. Marcus and MacKuen showed thus that emotions can both directly enter political judgments and have an indirect impact by influencing 
the processing of information. Corroboration for the influences of emotion on political cognition comes mainly from survey studies (e.g., Sniderman, Brody, \& Tetlock, I99I) as well as experimental designs (e.g., Brader, 2005; Civettini \& Redlawsk, 2009).

Overall, the current state of research implies that emotions can impact political judgments in two different ways. First, citizens can use their emotions as a piece of information for the evaluation of a politician, a party, or a proposal. In this vein, cognitive and affective information have an independent effect on political judgments. Accordingly, the outputs of the cognitive and the affective systems are considered to be additively integrated into a global evaluation. Beliefs and feelings should hence be implemented as main effects into statistical models. Second, affective and cognitive information can act together during processes of opinion formation. Emotions might, for instance, influence which cognitive beliefs are accessible and hence more likely to be used for subsequent judgments. Depending on the theoretical framework, this interplay of cognition and emotion can be modeled as a moderated or a mediated relationship (cf. Frazier, Tix, \& Barron, 2004). As the affective priming approach suggests that cognitions and emotions interact during decision making, we focus on their interactive (i.e., moderated) effects on political judgments in the remainder of this article.

\section{How Affective Priming Works}

In the previous section, it has been argued that emotions can influence political judgments in different ways. Affective priming is one possible process through which emotions can impact political evaluations.

As has already been pointed out, cognitive priming is generally assumed to function through its influence on the accessibility of cognitive concepts in memory. The quintessence of this perspective is the idea that individuals come to a decision not by considering all relevant information (since their cognitive resources are limited), but only the information that is currently most accessible in their memory. To explain how political campaigns influence the accessibility of concepts, researchers have relied on the metaphor of associative networks (e.g., Price \& Tewksbury, 1997). According to this reasoning, memory consists of a network of concepts which are intertwined through associative connections (Collins \& Loftus, I975). Given the multitude of concepts an average person uses every day, associative networks are considered to be highly complex structures, consisting of uncountable nodes and associative connections. Therefore, an individual has rarely the chance to search its memory for all relevant information, but is forced to base his or her decisions on a selection of knowledge that comes to mind in a given situation. By priming a specific concept, it is suggested, an activating impulse 
from the concept to the adjacent memory nodes is released that temporarily increases the activation level of these concepts. In subsequent evaluation processes, the primed individual is thus able to link the activated concepts more easily to the object that is to be assessed. In other words, the likelihood of the primed concepts to be used as standards of evaluation is increased.

Bower and Forgas (Bower, I98I; Bower \& Forgas, 200I) argue that similar activation effects can be expected as a consequence of subjective affective states. To describe the affective influences on memory they expanded the associative network model with an additional (metaphorical) element: The emotion nodes. According to this, every individual's associative network has two general emotion nodes (one for positive and one for negative affect) that are each linked to object-specific evaluations and function as gateways for affective activation impulses. Thus, if an individual experiences an emotional reaction in response to a given situation, the corresponding emotion node is activated and acts as the source of an impulse traveling the associative paths to affectively congruent concepts. That is, positive mood should activate the general node for positive affect which, in turn, should activate positively valenced concepts. Conversely, negative mood should result in the activation of negative information.

We therefore argue that political campaigns entail cognitive and affective priming effects. The cumulative priming effects of campaigns are composed of singular priming instances where a recipient is exposed to campaign information. At each priming instance, cognitive and affective effects may emerge. Cognitive priming effects emerge, for instance, when campaign-related news semantically prime certain issue aspects. In addition, news reports may elicit affective reactions. According to the appraisal approach to emotion, messages may cause affective reactions by addressing emotional appeals to the recipient (e.g., Lazarus, I99I). For instance, an article about unemployment may focus on the risk of job loss and thereby induce fear. The induced emotions may, in turn, directly influence citizens' opinions about a political issue. That is, positive emotions may support a favorable judgment, whereas negative emotions promote negative verdicts. In addition to these direct effects of emotion, the affective priming approach specifies "indirect" or interactive effects of emotion: Campaign-induced affective reactions may indirectly influence political judgments by priming affect-congruent cognitions.

It should be noted that the term affective priming has been already applied by Lodge and Taber (2005) as well as Sheafer (2007). Our conceptualization of affective priming is compatible with, but more specific than the conception of Sheafer. According to this, the evaluative tone of media messages about an issue can color recipients' evaluations of the issue; a process which he terms affective pre-priming. Affective priming is then the subsequent step, in which 
these issue evaluations influence the assessment of a politician or a party. We agree with Sheafer that evaluations contained within media messages influence the valence of subsequent judgments. However, we would add that such effects may be mediated by cognitive and/or affective processes as well as their interaction. Put differently, media messages may influence the recipients' evaluations through his or her beliefs and/or emotions, as both carry an evaluative meaning (cf. Eagly \& Chaiken, I993). We specifically reserve the term affective priming for attitudinal effects which result from the activation of cognitions through media-induced emotions. Our understanding of affective priming is hence narrower than that of Sheafer.

The hot cognition hypothesis states that sociopolitical objects are always affect laden and that evaluations are hence automatically activated and prime cognitive content whenever an object is encountered (Lodge \& Taber, 2005). Lodge and Taber showed that automatic evaluations associated with political attitude objects can facilitate or inhibit the activation of cognitions. As they assume that such evaluative effects are a priori affective, they do not differentiate between the impact of cognitive and emotional evaluative reactions on judgment formation. We would argue that evaluative reactions are not necessarily equivalent to emotional reactions (i.e., evaluations may be cognitive). In contrast to the hot cognition hypothesis, we hence only refer to affective priming when emotions activate cognitive content. Accordingly, our research focuses on the interaction of cognitive and emotional evaluations during judgment formation. In addition, we also chose a different empirical approach than Lodge and Taber: Instead of conducting laboratory studies we are interested in documenting affective priming effects outside of the laboratory in a naturalistic setting of a political campaign.

\section{Hypotheses}

Our study aims at the investigation of the direct and interactive effects of emotion and cognition in the course of a political campaign. Our first hypothesis postulates that affective reactions (i.e., emotions towards an issue) have a direct impact on political judgments above and beyond the effect of cognitions (i.e., cognitive beliefs or arguments in favor of and against an issue). That is, we are expecting significant main effects of emotions (direct affective impact). This hypothesis is consistent with the affect as information approach which posits that affective reactions can directly enter judgments (e.g., Schwarz \& Clore, I983).

In addition to the direct affective influences, we expect affective priming effects. Our second hypothesis assumes an interaction between voters' emotions and cognitions, such that affective states can influence the availability of affect-congruent cognitive content during attitude formation 
(affective priming or interactive affective impact). That is, positive emotions should enhance the impact of positively valenced arguments (i.e., pro-arguments focusing the beneficial consequences of the proposal) on attitudes while negative emotions should enhance the impact of negatively valenced arguments (i.e., contra-arguments focusing negative consequences).

Finally, we are interested in how cognitive and affective influences on judgments change in the course of the campaign. The longitudinal perspective is employed because cognitive priming effects are generally assumed to manifest themselves in an increasing impact of the primed content over time (e.g., Krosnick \& Kinder, I990; Ladd, 2007). We are thus proposing that the influence of the issue-related arguments on judgment should increase in the course of the campaign. In addition, we advance the research question, whether the interactive effects of emotion and cognition do increase over time. This question is important as laboratory experiments have mainly focused on the swift and presumably short-lived effects of affective priming (cf. Forgas, 1995). In analogy to cognitive priming, one might assume that repeated and consonant affective responses towards a political candidate or an issue may chronically prime affect-congruent cognitions and thus strengthen the interaction between emotion and cognition over time. Having said that, the volatility of affective responses towards an attitude object may also undermine any cumulative effect, which should be reflected in a more or less stable interactive relationship over time.

\section{Methods}

\section{Context and Data}

Our analyses focus on a Swiss popular vote that was held on a reform of the corporate taxation in 2008. The proposal was completed by the Federal Council in 2005 and was approved by the Swiss parliament during 2006 and 2007. In March 2007 a referendum was requested by the Swiss people which resulted in the popular vote of 2008 and, eventually, in the acceptance of the proposal. Pivotal properties of the reform package were the mitigation of double taxation of dividends, the reduction of capital tax, and the tax relief on small and medium-sized enterprises (SMEs). To test our assumption, we used survey data from a two-wave panel survey $\left(n_{\mathrm{I}}=\mathrm{I} 25 \mathrm{I}, n_{2}=\mathrm{I00I}\right)$. The first wave was fielded in the beginning of the campaign (in early January 2008), the second wave just after the ballot had taken place (in late February 2008). Response rate I, calculated according to the American Association for Public Opinion Research standard definitions (2009) is $14.4 \%$, response rate 2 is $\mathrm{I} 6.8 \%$. The relatively low response rates may be ascribed to the high complexity of the corporate taxation issue which might have discouraged participation in the survey. This is backed up by the fact that $40 \%$ of all 
refusals were based on lack of interest in the issue. It should be noted, however, that response rates have been shown to be only weakly associated with demographic representativeness (e.g., Holbrook, Krosnick, \& Pfent, 2008). That is, the low response rate may only pose a minor problem for the generalizability of empirical findings.

\section{Measures and Analysis}

Using computer-assisted telephone interviewing, participants were asked which arguments in favor of and against the reform they approved and what emotions towards the reform they experienced. ${ }^{1}$ Approval of the central arguments (e.g., "This tax reform advances investments and creates new jobs," "This tax reform brings unacceptable tax losses for the federal government and the cantons") was measured using 5-point rating scales (I "do not agree at all" to 5 "totally agree").

Similarly, to measure positive and negative emotions, participants were asked to indicate how much they agreed with statements describing emotional reactions towards the reform (e.g., "I am angry that income from investment of capital is privileged over earned income," "I am happy that the tax reform solves a major problem for SMEs"). That is, the emotional indicators asked the participants if certain aspects of the reform are associated with positive or negative emotions. A two-dimensional measurement of emotion was chosen because it has been demonstrated that individuals may experience both positive and negative emotions towards the same politician or political issue (e.g., Abelson et al., I982; Conover \& Feldman, 1986). This may be particularly true in the present case, as the corporate taxation reform features various aspects that may be associated with different emotional reactions. The two-dimensional structure of emotion is supported by the confirmatory factor analysis we conducted (cf. next section).

It should be noted that our measures of argument approval are purely cognitive as they address certain beliefs about the reform (e.g., "This tax reform advances investments and creates new jobs"). Admittedly, they exhibit an evaluative component, but evaluation is not identical to affect. In fact, cognitions as well as affect may exhibit an evaluative component (Eagly \& Chaiken, I993) and affective priming effects even require that cognitions exhibit a certain valence or evaluative meaning. The evaluative nature of a measure hence does not imply that the measure is affective. According to

\footnotetext{
${ }^{1}$ Means and standard deviations in wave 2 are: Age $(M=48.59, S D=16.59)$, left-right-ideology $(M=6.16, S D=2.13)$, satisfaction with income $(M=4.07, S D=0.89)$, interest in tax reform $(M=3.82$, $S D=\mathrm{I} .05)$, pro argument approval $(M=3.46, S D=\mathrm{I} .09)$, contra argument approval $(M=2.88, S D=\mathrm{I} . \mathrm{I} 3)$, positive emotion $(M=3.32, S D=$ I.I2 $)$, negative emotion $(M=3.76, S D=$ I.I3 $)$.
} 
Wyer, Clore, \& Isbell (I999) "affect refers to the positively or negatively valenced subjective reactions that a person experiences at a given point in time. These reactions are experienced as either pleasant or unpleasant feelings." (p. 3). That is, affective evaluations are conveyed through experienced feelings. Cognitive evaluations, on the other hand, are semantically conveyed. Accordingly, our affective measures ask the respondents if they experience an emotional reaction with regard to the corporate taxation reform (e.g., "I am angry that income from investment of capital is privileged over earned income"). There may be some overlap between the cognitive and affective indicators, but it must be stressed that they are not redundant with regards to content. Individuals may, for instance, think that the tax reform will entail tax losses without being emotionally concerned about them. To test the construct validity of our affective and cognitive measures, we conducted a confirmatory factor analysis using AMOS I8. Approval of pro and contra arguments, as well as positive and negative emotions were modeled as four latent variables. The results are depicted in Figure I.

The model shows a good fit to the data: $\chi^{2}$ (I2) $=18.75, n s$, comparative fit index $=.997$, root mean square error of approximation $=.024, p$ value for test of close fit $=.985$, standardized root mean square residual $=$. o 6 . As expected, positive and negative emotions are negatively correlated. Similarly, pro and contra arguments exhibit a negative relationship. However, the moderate level of the within-cognition and within-emotion associations suggests that neither cognitions nor emotions are bipolar constructs. Of special interest are the relations between argument approval and experienced emotions: There

Figure I

Confirmatory factor model for emotions and arguments in mave I. All coefficients are significant on a significance level of $p<.00 \mathrm{I}$

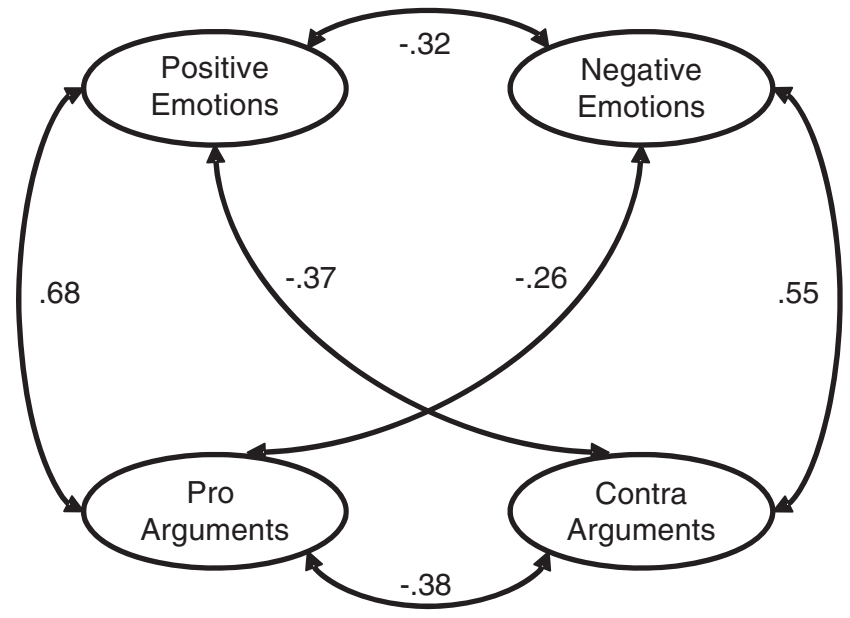


are considerable associations between arguments and emotions. Experiencing positive emotions is positively correlated with the approval of pro arguments and negatively correlated with the approval of contra arguments. Similarly, negative emotions are positively associated with contra argument approval and negatively related to pro argument approval. The confirmatory factor analysis hence supports the notion that emotions and arguments are related but discrete constructs. The results are in line with previous findings on the structure of political cognition and emotion (e.g., Breckler \& Wiggins, I99I; Ottati et al., I992).

For the regression analyses, the singular argument and emotion indicators were combined into four mean indices for each wave (pro and contra argument approval, positive and negative emotions towards the reform). All computed indices exhibit a fair reliability. ${ }^{2}$ To test for interactive effects of emotions and cognitions, two interaction terms were computed for each wave by multiplying the pro argument index with the positive emotion index and the contra argument index with the negative emotion index. In addition, curvilinear effects were controlled by adding squares of the argument and emotion indices into the regression. This approach was employed because omitted curvilinear relationships can lead to spurious interactions or obscure true interactions when the constitutive indicators of the interactions are correlated (as it is the case here) (Ganzach, I997). All indices were mean-centered prior to computing the interactions and the quadratic terms to alleviate the interpretation of the results. ${ }^{3}$ It should be noted that we found no evidence for excessive multicollinearity. The variance inflation factors for all argument and emotion indices and their combinations showed values ranging between I.3 and 3.o. Thus, the critical threshold of ı.o (Cohen, Cohen, West, \& Aiken, 2003) was not exceeded.

The dependent variable "global evaluation of the corporate taxation reform" was measured by asking participants to report their agreement with the statement "I am in favor of tax reliefs for business enterprises" ( Io-point rating scale, I "do not agree" to Io "completely agree"). The question wording was: "We would now like to know what you are thinking about the issue of corporate taxation reform in general." That is, we instructed individuals to report their overall attitude toward the reform. As the question wording did not refer to specific aspects of the reform (i.e., specific arguments) or emotional experiences, the measure is purely evaluative

\footnotetext{
${ }^{2}$ Reliabilities in waves I and 2 are: Pro arguments $\left(\alpha_{\mathrm{WI}}=.75 ; \alpha_{\mathrm{W} 2}=.82\right)$, contra arguments $\left(\alpha_{\mathrm{wI}}=.59\right.$; $\left.\alpha_{\mathrm{w} 2}=.68\right)$, positive emotion $\left(\alpha_{\mathrm{wI}}=.69 ; \alpha_{\mathrm{w} 2}=.80\right)$, negative emotion $\left(\alpha_{\mathrm{wI}}=.67 ; \alpha_{\mathrm{w} 2}=.7 \mathrm{I}\right)$.

${ }^{3}$ As the regression analyses contain interaction terms, the "main" effects of the centered predictors may be interpreted as the average effect of the predictors across all values of the respective moderator (cf. Cohen, Cohen, West, \& Aiken, 2003).
} 
(cf. Eagly \& Chaiken, I993; Haddock et al., I993). Identical measures of global evaluation have been employed in various studies in the fields of public opinion and attitude research (e.g., Abelson et al., I982; Haddock et al., I993; Kim, Han, \& Scheufele, 20го).

In addition, several covariates were measured with single items: Sex, age, education, left-right orientation, satisfaction with income, and interest in the tax reform. The data were analyzed using moderated hierarchical linear regression analyses. For each wave, we successively entered covariates, approval of pro and contra arguments, and positive and negative emotions towards the reform as predictors of the global evaluation of the taxation package into the regression. Finally, the four squares and two interactions of the argument and emotion indices were entered into the models. Estimating a regression model for each wave enabled us to investigate the changing impact of our predictors on the attitude toward the corporate taxation reform over time. By comparing the regression weights of predictors between waves, we follow a standard procedure in priming research (Bartels, 2006; Krosnick \& Kinder, I990; Ladd, 2007).

Following the regression analyses, we probed the interactions to achieve a better understanding of their form with the MODPROBE macro (Hayes \& Matthes, 2009). The macro allows for the identification of the direction and the significance of an independent variable's regression coefficient at different levels of the moderator (i.e., the complete range of values the moderator actually takes). In other words, we took a look at the influence of argument approval on issue evaluation at different levels of emotional reaction towards the tax reform.

\section{Results}

Results for the two hierarchical regression analyses are shown in Table I. ${ }^{4}$ Depicted are the results of the final regression after the entry of all variables and the incremental $R^{2}$ for each block of variables. Inspecting the covariates, the results suggest that socio-demographic variables did not significantly affect the global evaluation of the issue before or after the vote. Left-right ideology, on the other hand, has a significant impact in both waves. Individuals who located themselves on the right wing supported the tax reform more strongly than left-wing individuals-a suggestive result considering tax reliefs were a pivotal component of the reform. In wave 2 , interest in the tax reform

\footnotetext{
${ }^{4} \mathrm{~A}$ comparison of the respondents and non-respondents of wave 2 showed no substantial differences. In wave I, the two groups did not differ with respect to their level of positive or negative emotions, approval of pro or contra arguments or support of the corporate taxation reform. However, non-respondents were on average younger than respondents ( 42 vs. 52 years) and were more often working full time $\left(5^{8}\right.$ vs. $\left.39 \%\right)$. This implies that non-response was probably not associated with a certain opinion about the taxation reform, but with the available time resources of the respondent.
} 
Table I

Hierarchical Regression Analyses of Evaluation of Corporate Taxation Reform

Predictors $\quad \frac{\text { Wave I }}{\mathrm{B} \quad \beta} \frac{\text { Wave } 2}{\mathrm{~B}}$

Block I: Demographics

Sex $(\mathrm{I}=$ male, $2=$ female $)$

Age

Education

Block 2: Political predispositions

$\begin{array}{lllrr}\text { Left-right ideology }(\mathrm{I}=\text { left, } \text { Io }=\text { right }) & . \mathrm{I} 9 \mathrm{I}^{* *} & . \mathrm{I} 7 \mathrm{I}^{* *} & . \mathrm{IO} 4^{*} & .098^{*} \\ \text { Satisfaction with income } & .0 \mathrm{I} 2 & .004 & -. \mathrm{I} 9 \mathrm{O}^{*} & -.070^{*}\end{array}$

Interest in tax reform

$.026 \quad .0 \mathrm{II} \quad . \mathrm{I} 94^{*} \quad .088^{*}$

Block 3: Arguments

Business benefits (pro arguments)

Tax losses (contra arguments)

Block 4: Emotions

Positive emotions towards reform

Negative emotions towards reform

Block 5: Quadratic terms

Pro arguments (squared)

Contra arguments (squared)

Positive emotions (squared)

Negative emotions (squared)

Block 6: Interactions

Positive emotions $\times$ pro arguments

Negative emotions $\times$ contra arguments

Block I Incremental $R^{2}$

Block 2 Incremental $R^{2}$

Block 3 Incremental $R^{2}$

Block 4 Incremental $R^{2}$

Block 5 Incremental $R^{2}$

Block 6 Incremental $R^{2}$

$\begin{array}{rrrr}-.034 & -.007 & -.057 & -.012 \\ .000 & -.001 & -.006 & -.040 \\ .005 & .007 & -.006 & -.009\end{array}$

Total $R_{\text {Adjusted }}^{2}$

$$
\begin{array}{crrr}
.42 \mathrm{I}^{* * *} & .190^{* * *} & .478^{* *} & .226^{* * *} \\
-. \mathrm{I} 83^{*} & -.085^{*} & -. \mathrm{I} 8^{\#} & -.058^{\#}
\end{array}
$$$$
.62 \mathrm{I}^{* *} \quad .274^{* *} \quad .506^{* *} \quad .246^{* *}
$$$$
-.245^{*}-.1 \mathrm{I} 6^{*}-.239^{*}-. \mathrm{II} 7^{*}
$$$$
\begin{array}{llll}
.174^{*} \quad .105^{*} \quad .079 \quad .048
\end{array}
$$$$
\begin{array}{llll}
-.056 & -.034 & .130^{*} & .08 I^{*}
\end{array}
$$$$
\begin{array}{llll}
.0 I I & .007 & -.070 & -.044
\end{array}
$$$$
\begin{array}{llll}
-.010 & -.007 \quad .044 \quad .03 \mathrm{I}
\end{array}
$$

\begin{tabular}{|c|c|c|}
\hline-.026 & -.015 &. $\mathrm{I} 8 \mathrm{I}^{*}$ \\
\hline $.03 \mathrm{I}$ & .017 & -. I I 6 \\
\hline \multicolumn{2}{|c|}{.005} & .004 \\
\hline & $7^{* *}$ & $.136^{* * *}$ \\
\hline & $9^{* *}$ & $.132^{* * *}$ \\
\hline & $8 * *$ & $.044^{* * *}$ \\
\hline & & $.015^{* * *}$ \\
\hline & & $.006^{*}$ \\
\hline & & .326 \\
\hline
\end{tabular}

Note. $\mathrm{B}$ values and $\beta$ s refer to the final coefficients after the entry of all variables.

${ }^{\#} p<$. Io, ${ }^{*} p<.05, * *{ }^{*} p<.001$.

increased approval of the reform package, whereas satisfaction with income reduced approval. Altogether, political predispositions accounted for $13.7 \%$ and $\mathrm{I} 3.6 \%$ of variance in waves $\mathrm{I}$ and 2 respectively.

Our first hypothesis posits that emotions and argument approval should exert distinct influences on issue evaluation (direct affective impact). The regression analyses support this notion. As expected, the approval of arguments regarding business benefits increases support for the reform package in both waves, whereas approval of contra arguments has an adverse effect. Similarly, positive emotions towards the reform increase support, whereas 
negative emotions decrease support. Interestingly, emotions turn out to be better predictors of issue evaluation than argument approval. In both waves, the beta coefficients of positive and negative emotions are higher than the beta coefficients for the approval of pro and contra arguments. Furthermore, it should be noted that pro arguments and positive emotions are better predictors of issue evaluation than contra arguments and negative emotions. We will address this finding in the discussion section.

Our results support the hypothesis that people's affective reactions directly influence political judgments. The findings also provide evidence of direct affective influences that are independent of the impact of cognitions and even stronger than the cognitive effects. Obviously, voters relied more on their feelings than on their cognitive beliefs when evaluating the corporate taxation reform. This result is in line with findings in previous studies that emotions can directly inform political judgments (e.g., Abelson et al., 1982; Haddock \& Zanna, I998).

It should also be noted that we found some evidence for curvilinear effects of emotion and cognition on issue evaluation (see Table I, block 5). More precisely, the linear effects of emotion and cognition were sometimes accompanied by some degree of convexity. However, in the absence of any hypotheses about quadratic effects, we will confine the further discussion to the theoretically postulated interaction effects and treat the quadratic terms as mere covariates, employed to preclude spurious or suppressed interactions of emotion and cognition.

To test for the moderation of argument approval's attitudinal influence by emotion (affective priming), we entered the interaction terms in the last block of the regression. The interaction between pro argument approval and positive emotion had a significant impact on issue evaluation in wave 2 . The positive sign of the term implies that the positive effects of the pro arguments on evaluation increase when participants experience strong positive emotions. To gain a better understanding of the interaction, we plotted the size of the pro arguments' regression coefficient against the values of the moderator (i.e., the positive emotion index). The results are depicted in Figure 2.

Depicted are the areas of significance and non-significance that denote at which values of the moderator the pro arguments have a significant impact on the evaluation of the tax reform. As can be seen, pro arguments have no influence on evaluation when individuals experienced only faint positive emotions. As positive affect increases, however, the attitudinal impact of the pro arguments grows steadily. More precisely, pro arguments have a significant effect for individuals whose measurement of positive emotion is less than I.20 scale points below the empirical mean (i.e., for $80 \%$ of the sampled individuals). 
Figure 2

Size of the regression coefficient for pro arguments (mith $95 \%$ confidence interval) plotted against empirical values of the moderator (positive emotions) in mave 2

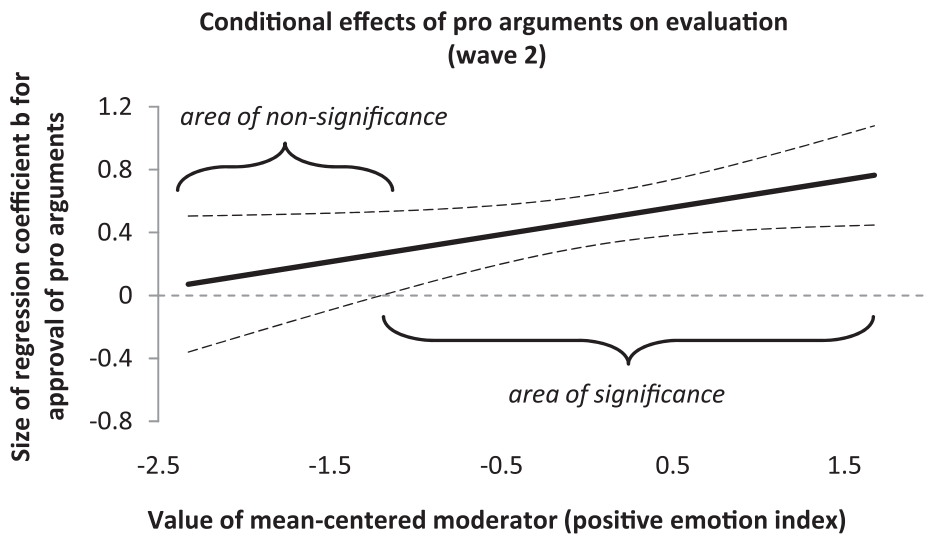

Figure 3

Size of the regression coefficient for contra arguments (mith $95 \%$ confidence interval) plotted against empirical values of the moderator (negative emotions) in mave 2

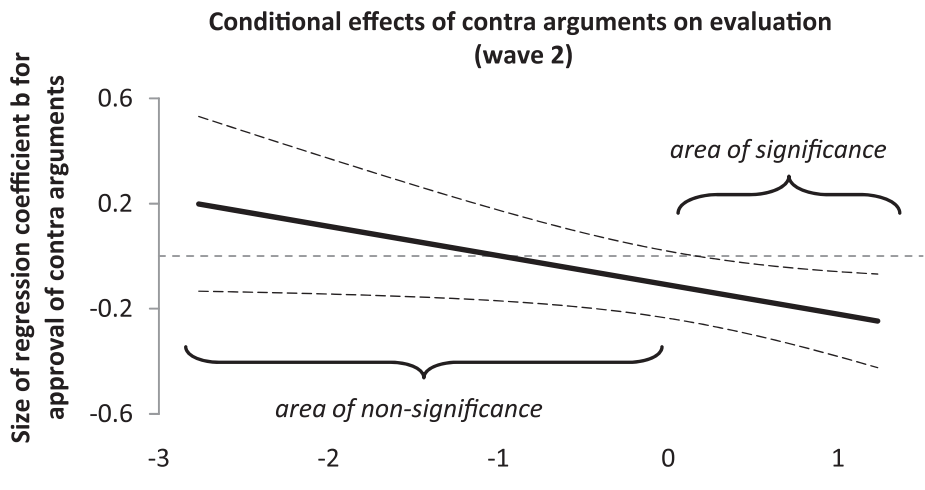

Value of mean-centered moderator (negative emotion index)

The interaction between contra arguments and negative emotion on issue evaluation is significant in the second wave too. Contra arguments influence the evaluation of the reform proposal only when negative emotion is at least o. I67 scale points above the empirical mean (i.e., for $56 \%$ of the sampled individuals). Thus, contra arguments only have an influence on the attitude towards the tax proposal when individuals experienced relatively strong negative affect. Our affective priming hypothesis is hence supported for wave 2 .

Finally, we were interested in how the impact of cognitions and emotions changes over time. In terms of cognitive priming, one expects that the 
attitudinal impact of cognitions increases in the course of the campaign. As Table I shows, the impact of pro and contra arguments grows only marginally from wave I to wave 2: The amount of variance explained by the arguments rises from II.9 to $13.2 \%$. However, significance tests of the differences between the regression coefficients did not indicate any significant increase. A different picture emerges when we consider the change in the cognitiveaffective interaction terms from the first to the second panel wave. In the first wave, neither interaction is statistically significant. In the second wave, the interaction between pro arguments and positive emotions as well as the interaction between contra arguments and negative emotions is significant. That is, affective priming effects are only found in the end of the campaign. Accordingly, significance tests indicate that the two interaction terms significantly increased over time $(p<.05)$. All in all, we found no clear evidence for cognitive priming, but were able to demonstrate cumulative affective priming. Apparently, the political campaign did not successively prime people's cognitive beliefs, but evoked positive and negative emotions that increasingly activated arguments regarding the reform.

\section{Discussion}

The present study clearly shows that emotions can both directly and indirectly influence people's attitude towards proposals like the corporate taxation reform. The finding is particularly intriguing as emotions exerted a substantial direct effect on the evaluation of the corporate taxation reform (see Table I, block 4), even though the issue was quite dry, technical and, at first glance, unlikely to provoke intense emotional reactions. Having said that, the complexity of the proposal might just have facilitated affective influences. Participants may have relied on their feelings because the complexity of the proposal hindered them to integrate the pivotal arguments into a coherent opinion. This interpretation is suggestive as the affect-as-information approach postulates the use of the affect heuristic whenever an individual is not motivated or-due to cognitive restraints-not able to elaborate available information (cf. Forgas, I995; Schwarz \& Clore, I983). The high complexity of the tax issue is also the most likely reason why emotions exerted a stronger influence on the evaluation of the reform package than argument approval (see Table I, blocks 3 and 4). When people are not motivated and/or not able to comprehend a political issue, the attitudinal impact of the affect heuristic should increase because their emotions may be the only reliable and intelligible source of information. At the same time, the influence of arguments which the majority of the electorate does not understand should diminish because the issue complexity impedes a rational weighing of these arguments. Consequently, emotions should have a substantial impact on the evaluation of an overly complex issue. 
Interestingly, positive information (i.e., pro arguments and positive emotions) had a bigger impact on the evaluation of the reform than negative information (see Table I, blocks 3 and 4 ). This result is contrary to a bulk of studies which indicate a negativity bias in judgment formation (e.g., Peeters \& Czapinski, I990). However, it has been argued that the relationship between a valenced message and judgment is mediated by the informativeness of the message. That is, positive information can be more influential during judgment formation if it is more diagnostic for a judgment (e.g., Skowronski \& Carlston, I989). In the corporate taxation campaign, pro arguments may have been perceived as more informative as they addressed direct consequences of the reform package (e.g., the advancement of investments and creation of new jobs). The arguments that were brought forward by the contra camp, on the other hand, focused on consequences that are more indirect and remote (e.g., potential negative long-term effects for the social insurance system). That is, the arguments of the pro camp may have been more persuasive as they addressed immediate instead of alleged long-term consequences of the reform.

The stronger influence of positive emotions is in line with findings on the asymmetrical effects of positive and negative emotion on judgment. According to this, positive affect triggers heuristic processing, whereas negative affect promotes systematic processing (e.g., Schwarz \& Clore, I983). Positive affect is thus more likely to be used as a judgment heuristic and may have more pronounced (direct) effects on opinion formation than negative affect. Similarly, the affective intelligence approach posits that enthusiasm instructs individuals to pay little attention to political events and rely on shortcuts (Marcus \& MacKuen, I993). Political campaigns may hence promote or impede detailed examination of information by inducing positive or negative emotions which has also implications for the impact of emotions on judgment.

Extending previous findings of public opinion research on the direct effects of emotions, we were also able to find support for the affective priming hypothesis: Positive and negative emotions increased the impact of similarly valenced arguments on judgment - albeit only in the end of the campaign (see Table I, block 6). More specifically, positive emotions raised the importance of pro arguments for the attitude towards the tax proposal. Similarly, negative emotions increased the attitudinal impact of contra arguments. This result makes clear that emotions do not only directly inform voters about their preferences. They also have an indirect effect on attitudes by increasing the accessibility of affect-congruent beliefs during opinion formation. This result goes beyond findings of previous survey studies and corroborates evidence provided by experimental studies (e.g., Bower \& Forgas, 200I).

The plots of the interactions revealed a surprising picture: Some level of positive and negative emotional activation was necessary in order that the pro 
and contra arguments could exert their impact on the evaluation of the reform package (see Figures 2 and 3). Campaigns are thus able to affectively prime the use of certain arguments which might not be used by voters otherwise. It is open to discussion how such affective priming effects are evaluated in the light of the demands of democratic deliberation. We may interpret this affective priming effect positively as emotions may enable individuals to draw from their knowledge reservoirs facilitating a political judgment about a difficult issue like the tax proposal. On the other hand, this finding may be criticized as the result of manipulative emotionalized communication. Whatever position is favored, it is apparent that emotionalized communication is a powerful tool for political campaigners. Our findings implicate that political campaigns should be particularly effective when they communicate arguments in favor of one's own position and elicit congruent emotions towards the issue. Proponents of an issue should, for instance, be interested in communicating pro arguments and eliciting positive emotions. The latter should not only directly increase the evaluation of the issue at hand but also indirectly enhance the impact of the pro arguments.

We also found evidence for cumulative affective priming effects: Emotions primed arguments only in the end of the campaign (see Table I, block 6). The results bridge experimental findings on affective priming with survey studies on opinion formation in political campaigns. Experimental studies have repeatedly demonstrated that affect may influence the accessibility of cognitions. Our findings show, in addition, that individual and for that matter rather weak affective priming effects may add up during the course of a campaign. This, in turn, can produce a chronic accessibility of affect-congruent arguments. Thus, affective priming is presumably an effect that requires a certain time frame to build up. Individual affective priming effects are unlikely to have a lasting effect on cognition. Rather, a repeated induction of emotions is necessary to increase the chronic accessibility of affect-congruent cognitions.

Finally, we have to address some limitations of this study. First, one might object that the identified affective priming effects demonstrated are rather weak. With less than $\mathrm{I} \%$ of explained variance the affective priming effect appears negligible. It should however be noted that owing to methodological constraints interactive effects are especially hard to identify in survey designs and even effects explaining only small quantities of variance should be considered as important (McClelland \& Judd, I993; Morris, Sherman \& Mansfield, 1986). Furthermore, when we consider the result of the referendum, then even this small effect might have had considerable consequences. The tax proposal received only a small majority of $50,5 \%$ of the votes. In this close run, affective priming effects might have been the crucial factor in deciding the vote. 
Second, we were not able to find substantive evidence for the generally well corroborated campaign priming effects. The amount of variance explained by cognitive beliefs (i.e., the approval of arguments) only increased marginally. How can the missing effects be explained and reconciled with the previous findings on campaign priming? On the one hand, it should be noted that the interval between the panel waves was rather short. The first wave took place in early January and the second wave in the end of February. Compared with the interpanel intervals of several months in American National Election Studies, this time lag might have been too short to produce stronger cognitive priming effects. On the other hand, as has been already argued, the corporate taxation reform might have been too complicated to be understood by the people. Its complexity might have impeded learning processes which may be the reason for the relative stability of argument approval's impact on the attitude towards the proposal.

Finally, our findings on cumulative affective priming effects have to be discussed. The question if affective priming effects are cumulative or not, is probably an empirical issue. Cumulative effects are expected when a politician or issue repeatedly evokes consonant affective reactions so that the singular priming instances can add up and augment the chronic accessibility of affect-congruent cognitions. Cumulative effects might be inhibited, on the other hand, if the emotional reactions towards a political object vary in the course of a campaign. Further studies are needed to establish the conditions under which affective priming effects occur and are expected to consolidate over time. A closer look at the dynamics of a campaign should prove to be useful as the affective primes of a conflictive campaign might cancel each other out while consonant primes might reinforce each other. Furthermore, individual differences should be considered. Several possible moderators of affective influence like the cognitive abilities and motivation of the individual to process information have already been addressed in the previous sections and their impact is well documented in experimental studies (cf. Forgas, I995; Schwarz \& Clore, I983). As Forgas (1995) points out, for instance, direct and indirect influences of emotions on evaluations are linked to the depth of information processing which is used to form an opinion. This examination of the conditions of affective influences on political judgments is particularly important as it may shed light on the classical question if and when emotions are detrimental or beneficial for political decision making.

\section{Acknowledgments}

This work was supported by a grant from the Swiss National Science Foundation as a part of the National Center of Competence in Research (NCCR) "Challenges to Democracy in the 2ist Century". 


\section{References}

Abelson, R. P., Kinder, D. R., Peters, M. D., \& Fiske, S. T. (1982). Affective and semantic components in political person perception. Fournal of Personality and Social Psychology, 42, 6i9-630.

American Association for Public Opinion Research (2009). Standard definitions: Final dispositions of case codes and outcome rates for surveys (6th ed.). Lenexa, KS: AAPOR.

Bartels, L. M. (2006). Priming and persuasion in presidential campaigns. In H. E. Brady \& R. Johnston (Eds.), Capturing campaign effects (pp. 78-II2). Ann Arbor, MI: University of Michigan Press.

Bower, G. H. (198I). Mood and memory. American Psychologist, 36(2), I29-I48.

Bower, G. H., \& Forgas, J. P. (200I). Mood and social memory. In J. P. Forgas (Ed.), Handbook of affect and social cognition (pp. 95-I20). Mahwah, NJ: Erlbaum.

Brader, T. (2005). Striking a responsive chord: How political ads motivate and persuade voters by appealing to emotions. American fournal of Political Science, $49,388-405$.

Breckler, S. J., \& Wiggins, E. C. (I99I). Cognitive responses in persuasion: Affective and evaluative determinants. Fournal of Experimental Social Psychology, 27, I80-200.

Civettini, A. J. W., \& Redlawsk, D. P. (2009). Voters, emotions, and memory. Political Psychology, 30(I), I25-I5I.

Cohen, J., Cohen, P., West, S. G., \& Aiken, L. S. (2003). Applied multiple regression/ correlation analysis for the behavioral sciences (3rd ed.). Mahwah, NJ: Erlbaum.

Collins, M. A., \& Loftus, E. F. (1975). A spreading-activation theory of semantic processing. Psychological Reviem, 82, 407-428.

Conover, P. J., \& Feldman, S. (I986). Emotional reactions to the economy: I'm mad as hell and I'm not going to take it anymore. American fournal of Political Science, $30(\mathrm{I}), 50-78$.

Damasio, A. (1994). Descartes' error. New York, NY: Putnam's Sons.

De Castella, K., McGarty, C., \& Musgrove, L. (2009). Fear appeals in political rhetoric about terrorism. An analysis of speeches by Australian Prime Minister Howard. Political Psychology, 30(I), I-26.

de Vreese, C. H. (2004). Primed by the Euro: The impact of a referendum campaign on public opinion and evaluations of government and political leaders. Scandinavian Political Studies, $27(\mathrm{I}), 45^{-64}$.

Druckman, J. N. (2004). Priming the vote: Campaign effects in a U.S. senate election. Political Psychology, 25, 577-594.

Eagly, A. H., \& Chaiken, S. (1993). The psychology of attitudes. Fort Worth, TX: Harcourt Brace Jovanovich.

Forgas, J. P. (I995). Mood and judgment. The affect infusion model (AIM). Psychological Bulletin, II 1 (I), 39-66.

Frazier, P. A., Tix, A. P., \& Barron, K. E. (2004). Testing moderator and mediator effects in counseling psychology research. Fournal of Counseling Psychology, 5I(I), II $5^{-1} 34$.

Ganzach, Y. (I997). Misleading interaction and curvilinear terms. Psychological Methods, 2(3), 235-247. 
Granberg, D., \& Brown, T. A. (I989). On affect and cognition in politics. Social Psychology Quarterly, 52(3), I7 I-I82.

Haddock, G., \& Zanna, M. P. (I998). Assessing the impact of affective and cognitive information in predicting attitudes toward capital punishment. Law and Human Behavior, 22, 325-339.

Haddock, G., Zanna, M. P., \& Esses, V. M. (I993). Assessing the structure of prejudicial attitudes: The case of attitudes toward homosexuals. Fournal of Personality and Social Psychology, 65, I I05-i i 8.

Hayes, A. F., \& Matthes, J. (2009). Computational procedures for probing interactions in OLS and logistic regression: SPSS and SAS implementations. Behavior Research Methods, 4I, 924-936.

Holbrook, A. L., Krosnick, J. A., \& Pfent, A. (2008). The causes and consequences of response rates in surveys by the news media and government contractor survey research firms. In J. M. Lepkowski, C. Tucker, J. M. Brick, E. de Leeuw, L. Japec \& P. J. Lavrakas, et al. (Eds.), Advances in telephone survey methodology (pp. 499-528). Hoboken, NJ: Wiley.

Iyengar, S. (I990). The accessibility bias in politics: Television news and public opinion. International Fournal of Public Opinion Research, 2(I), I-I 5.

Iyengar, S., \& Kinder, D. R. (1987). Nems that matters: Television and American opinion. Chicago, IL: University of Chicago Press.

Jerit, J. (2004). Survival of the fittest: Rhetoric during the course of an election campaign. Political Psychology, 25, 563-575.

Ju, Y. (2005). Policy or politics? A study of the priming of media frames of the South Korean President in the public mind. International fournal of Public Opinion Research, I8(I), 49-66.

Kim, S.-H., Han, M., \& Scheufele, D. A. (2010). Thinking about him this way: Priming, news media, and South Koreans' evaluation of the president. International Journal of Public Opinion Research, 22(3), 299-3 I9.

Krosnick, J. A., \& Kinder, D. R. (I990). Altering the foundations of support for the president through priming. American Political Science Reviem, 84, 497-5I2.

Ladd, J. M. (2007). Predispositions and public support for the president during the war on terrorism. Public Opinion Quarterly, 7I, 5I I-538.

Lazarus, R. S. (I99I). Emotion E adaptation. Oxford: Oxford University Press.

LeDoux, J. E. (I999). The emotional brain: The mysterious underpinnings of emotional life. London: Phoenix.

Lodge, M., \& Taber, C. S. (2005). The automaticity of affect for political leaders, groups, and issues: An experimental test of the hot cognition hypothesis. Political Psychology, 26, 455-482.

Marcus, G. E., \& MacKuen, M. B. (I993). Anxiety, enthusiasm, and the vote: The emotional underpinnings of learning and involvement during presidential campaigns. American Political Science Reviem, 87, 672-685.

Matthes, J. (2008). Media frames and political judgments. Exploring the boundaries of framing effects in a two-wave panel study. Studies in Communication Sciences, 8(2), IOI-I 28 .

McClelland, G. H., \& Judd, C. M. (I993). Statistical difficulties of detecting interactions and moderator effects. Psychological Bulletin, II 4, 376-390. 
McDermott, R. (2004). The feeling of rationality: The meaning of neuroscientific advances for political science. Perspectives on Politics, 2, 69I-704.

Morris, J. H., Sherman, J. D., \& Mansfield, E. R. (I986). Failures to detect moderating effects with ordinary least squares-moderated multiple regression: Some reasons and a remedy. Psychological Bulletin, 99, 282-288.

Ottati, V. C., Steenbergen, M. R., \& Riggle, E. (I992). The cognitive and affective components of political attitudes: Measuring the determinants of candidate evaluations. Political Behavior, I4, 423-442.

Peeters, G., \& Czapinski, J. (I990). Positive-negative asymmetry in evaluations: The distinction between affective and informational negativity effects. European Reviem of Social Psychology, I, 33-6o.

Price, V., \& Tewksbury, D. (I997). News values and public opinion: A theoretical account of media priming and framing. In G. A. Barnett \& F. J. Boster (Eds.), Progress in Communication Sciences. Vol. 13. Advances in Persuasion (pp. 173-212). Greenwich, CT: Ablex Publishing Corporation.

Rahn, W. M. (2000). Affect as information: The role of public mood in political reasoning. In A. Lupia, M. D. McCubbins \& S. L. Popkin (Eds.), Elements of reason. Cognition, choice, and the bounds of rationality (pp. I30-I50). Cambridge: Cambridge University Press.

Schwarz, N., \& Clore, G. L. (I983). Mood, misattribution, and judgments of well-being: Informative and directive functions of affective states. Fournal of Personality and Social Psychology, 45, 5'3-523.

Sheafer, T. (2007). How to evaluate it: The role of story-evaluative tone in agenda setting and priming. Fournal of Communication, 57, 2I-39.

Skowronski, J. J., \& Carlston, D. E. (I989). Negativity and extremity biases in impression formation: A review of explanations. Psychological Bulletin, I05(I), I3 I-I 42.

Sniderman, P. M., Brody, R. A., \& Tetlock, P. E. (I99I). Reasoning and choice: Explorations in political psychology. Cambridge: Cambridge University Press.

Way, B. M., \& Masters, R. D. (I996). Emotion and cognition in political information processing. Fournal of Communication, 46(3), 48-65.

Wyer, R. S., Jr., Clore, G. L., \& Isbell, L. M. (I999). Affect and information processing. Advances in Experimental Social Psychology, 3I, I-77.

Zajonc, R. B. (I980). Feeling and thinking: Preferences need no inferences. American Psychologist, 35(2), I 5 I-I75.

\section{Biographical Notes}

Rinaldo Kühne (MA, University of Zürich) is a $\mathrm{PhD}$ student at the Institute of Mass Communication and Media Research, University of Zürich, Switzerland. His research focuses on the process of public opinion formation, effects of emotions, media effects, and empirical methods.

Christian Schemer ( $\mathrm{PhD}$, University of Zürich) is a post-doc at the Institute of Mass Communication and Media Research, University of Zürich, Switzerland. His research 
focuses on the process of public opinion formation, effects of emotions, media effects, and empirical methods.

Jörg Matthes (PhD, University of Zürich) is full professor at the Department of Communication, University of Vienna, Austria. His research focuses on the process of public opinion formation, media effects, trust in news media, and empirical methods.

Werner Wirth ( $\mathrm{PhD}$, University of München) is full professor for communication and empirical media research at the Institute of Mass Communication and Media Research, University of Zürich, Switzerland. His research focuses on media effects, entertainment, media and emotions, interactive media, and empirical methods. 